\title{
Kinetics of exocytosis in adrenal chromaffin cells
}

\author{
Kevin D. Gillis*† and RobertH . Chow
}

Upon repetitive or maintained stimulation, chromaffin cells secrete catecholamines initially at a very high rate which then relaxes with multiple kinetic components. The complex kinetics are often modeled as resulting from the successive depletion of several functional pools of secretory granules which may reflect specific protein-mediated steps in granule maturation. The fastest compon ent represents granules fully primed for exocytosis. This 'readily releasable pool' may, under some circumstances, consist of only about a dozen granules which can be released within tens of milliseconds. M odulating the size of this pool may bean important way for cells to regulate secretion.

Key words: caged calcium / exocytosis / membrane capacitance measurements / permeabilized cells / readily releasable pool

(C)1997 Academic Press Ltd

Chromaffin cells and other neuroendocrine cells store substances destined for secretion in membranedelimited granules. These granules fuse with the plasma membrane and release their contents into the extra cellular space by exocytosis, a process that is thought to be triggered by a rise in intracellular $\mathrm{Ca}^{2+}$ concentration $\left(\left[\mathrm{Ca}^{2+}\right]_{\mathrm{i}}\right){ }^{1}$

A common feature of many secretory cells is that the rate of exocytosis declines precipitously upon repetitive or continuous stimulation (see e.g. refs 2-5). For example, when $\left[\mathrm{Ca}^{2+}\right]_{i}$ is stepped to a constant value in permeabilized chromaffin cells, an initially high rate of secretion is noted which progressively declines with time of exposure to the $\mathrm{Ca}^{2+}$ stimulus.

The most common interpretation of the transient nature of secretion is that only a limited number of

From the *Department of M embrane Biophysics, Max-Planck Institute for Biophysical Chemistry, Am Fassberg, D-37077 Göttingen, Germany, and $¥ D$ epartment of Physiology, University of Edinburgh M edical School, Teviot Place, Edinburgh, EH $89 A G$, Scotland, UK

Present address:

tDepartments of Electrical Engineering and Physiology, University of $\mathrm{M}$ issouri-Columbia, Dalton Cardiovascular Research Center, Research Park, Columbia, M 0 65211, USA

(C)1997 Academic Press L td

$1084-9521 / 97 / 020133+08$ f25.00/0/sr960132 secretory granules are in a 'readily releasable' state. This concept is reinforced by morphological studies which indicate that only a small percentage of secretory granules are in the immediate vicinity of the plasma membrane, ${ }^{6-8}$ which is presumably a prerequisite for quick release. The concept of the 'readily releasable pool' (RRP), however, is still evolving. For example, the relationship between a functionally defined pool of granules and a morphologically defined pool is still not certain ( however, see refs 7,8 ). In addition, ever smaller and faster-releasable pools are being described as the time resolution of assays of exocytosis improves. ${ }^{9-13}$

\section{A basic depletion model}

The most basic model for describing the kinetics of exocytosis is given by the following scheme: ${ }^{14}$

$$
\mathrm{A} \underset{\mathrm{k}_{-1}}{\stackrel{\mathrm{k}_{1}}{\rightleftharpoons}} \mathrm{B}^{\mathrm{k}_{2}} \mathrm{C}
$$

' $A$ ' is the 'reserve pool' which supplies a much smaller RRP (' $B$ ') in a reversible reaction. Exocytosis involves the irreversible reaction ( rate $k_{2}$ ) whereby granules from pool ' $B$ ' join the 'secreted pool' (' $C$ '). The rate of exocytosis is steeply $\mathrm{Ca}^{2+}$-dependent, ${ }^{10,15,16}$ with $\mathrm{k}_{2}$ believed to be proportional to the third or fourth power of $\left[\mathrm{Ca}^{2+}\right]_{i}$. Upon stimulation, a rise in $\left[\mathrm{Ca}^{2+}\right]_{i}$ leads to a dramatic enhancement of $\mathrm{k}_{2}$ and a high rate of exocytosis which is proportional to the size of ' $B$ '. This high rate cannot be sustained, however, because the rate of depletion of the RRP greatly exceeds the rate of refilling ( rate $_{1}$ ).

It is important to note that the terms 'early' and 'late' can have conflicting meanings in kinetic studies of exocytosis. In the context of the model, the granules are described as maturing from 'early' stages in the reserve pool to a 'late' readily releasable state. However, experimentally, what one observes with a strong maintained stimulus is an 'early' rapid phase of secretion from the RRP, followed by a slower 'late' phase, at which time the rate of secretion is limited by ('early') steps of granule mobilization.

The basic assumption of the model is that the 
decline in secretory rate is due to the depletion of the RRP. However, a reduction in the forward rate constant $\left(\mathrm{k}_{2}\right)$ due to a declining $\left[\mathrm{Ca}^{2+}\right]_{i}$ or a desensitization of the $\mathrm{Ca}^{2+}$ sensor could also account for a declining rate of secretion. In fact, a decline in $\left[\mathrm{Ca}^{2+}\right]_{i}$ does occur in response to the physiological agonist acetylcholine or depolarization with high $\left[\mathrm{K}^{+}\right]$, due to the inactivation of $\mathrm{Ca}^{2+}$ channels. ${ }^{13}$ Thus a certain amount of experimental control over $\left[\mathrm{Ca}^{2+}\right]_{i}$ and/ or $\mathrm{Ca}^{2+}$ influx is necessary in order to effectively probe the dynamics of secretion.

\section{Permeabilized cell studies}

The problem introduced by inactivation of $\mathrm{Ca}^{2+}$ channels can be bypassed by introducing pores in the membrane large enough to allow the equilibration of buffered $\mathrm{Ca}^{2+}$ solutions between the extracellular solution and the cytosol. In their pioneering experiments with this approach, Baker and Knight ${ }^{2}$ showed that a rapid increase in extracellular $\left[\mathrm{Ca}^{2+}\right]$ leads to a high rate of catecholamine secretion from chromaffin cells which then declines (Figure $1 \mathrm{~A}$ ).

A significant recent advance using permeabilized cells has been the demonstration that MgATP is involved in an early 'priming' step, but not in the final $\mathrm{Ca}^{2+}$-dependent 'triggering' step. ${ }^{17}$ As illustrated in Figure $1 \mathrm{~A}$, omitting MgATP during the triggering of secretion has little effect on the initial rapid phase of release, however, secretion terminates after about 4\% of total cell norepinephrine is released. ${ }^{15}$ This 'primed' component is absent if the cells are not exposed to MgATP immediately before the triggering step. ${ }^{17}$ Given that chromaffin cells contain $20,000-30,000$ granules, ${ }^{25}$ it can be estimated that about 1000 granules are 'primed' for exocytosis ( also see ref 7).

Different proteins are involved in 'priming' versus the subsequent 'triggering' step, lending support to the notion that the steps are distinct. ${ }^{18-20,23,38,42} \mathrm{~A} 20 \mathrm{~S}$ docking/fusion protein complex has been proposed to play an important role in exocytosis. ${ }^{22}$ Two components of this complex, the soluble ATPase NSF ( $\mathrm{N}$-ethylmaleimide-sensitive fusion protein) and aSNAP (soluble NSF attachment protein) have been implicated in priming. ${ }^{23}$ Two other proteins found in the complex, SNAP-25 and synaptobrevin, are selectively cleaved by the clostridial neurotoxins botulinum type A (BoTx-A) and tetanus toxin (TeTx), respectively. These toxins inhibit priming, but not triggering steps. ${ }^{42}$ The maintenance of polyphosphoinositide lipids appears to be another important component of the priming reaction. ${ }^{19-21}$ Proteins assigned to triggering steps include ' $\mathrm{p} 145$ ', ${ }^{18}$ protein kinase $\mathrm{C}^{38}$ and calmodulin. ${ }^{23}$

Bittner and Holz greatly extended the kinetic separation of the steps of exocytosis, showing that the initial rate of secretion is half-maximal between 30-100 $\mu \mathrm{M} \mathrm{Ca}{ }^{2+}$, whereas later rates of secretion (reflecting 'early' mobilization steps) are maximal by $10 \mu \mathrm{M} .{ }^{15}$ They also demonstrated a role for $\mathrm{Ca}^{2+}$ in the priming of exocytosis in addition to its accepted role in triggering exocytosis. ${ }^{15}$ Finally, a temperaturesensitive reaction was inferred to occur after ATP but before the final, $\mathrm{Ca}^{2+}$-dependent triggering step. ${ }^{24}$

Although great strides have been made with permeabilized cell studies, it was soon apparent that the limited time resolution of biochemical measurements of secretion (on the order of $5 \mathrm{~s}$ ) might not suffice for resolving the fastest components of secretion which reflect the final steps in exocytosis. Electrical assays of exocytosis have provided the crucial resolution.

\section{Membrane capacitance measurements}

Patch clamp techniques ${ }^{26}$ allow unprecedented experimental control over the triggering of secretion by allowing the membrane potential of an individual cell to be 'clamped' and the $\mathrm{Ca}^{2+}$ current which results from depolarizing pulses to be readily measured. Also, substances can be introduced into the cell through the patch pipette, such as buffered $\mathrm{Ca}^{2+}$ solutions. Patch clamp techniques can also be extended to monitor exocytosis with millisecond time resolution by electrical capacitance measurements of the cell membrane. ${ }^{27,28}$ The technique is illustrated in Figure 1B. Increases in capacitance accompany exocytosis because the granule membrane adds to the plasma membrane surface area. Conversely, decreases in capacitance accompany endocytosis. The principal disadvantage of the capacitance approach is that only the difference between exocytosis and endocytosis is reported. Since endocytosis usually begins with a lag after exocytosis is triggered, ${ }^{9,10,40,43}$ earlier phases of exocytosis are probably more reliably monitored than later phases. ${ }^{40}$

Experiments using capacitance measurements revealed that depolarization-evoked exocytosis can occur with initial rates approaching 1000 granules per second $^{29}$ - an order of magnitude faster than estimated using permeabilized cells. ${ }^{15}$ Application of trains of depolarizing pulses often reveal a declining 

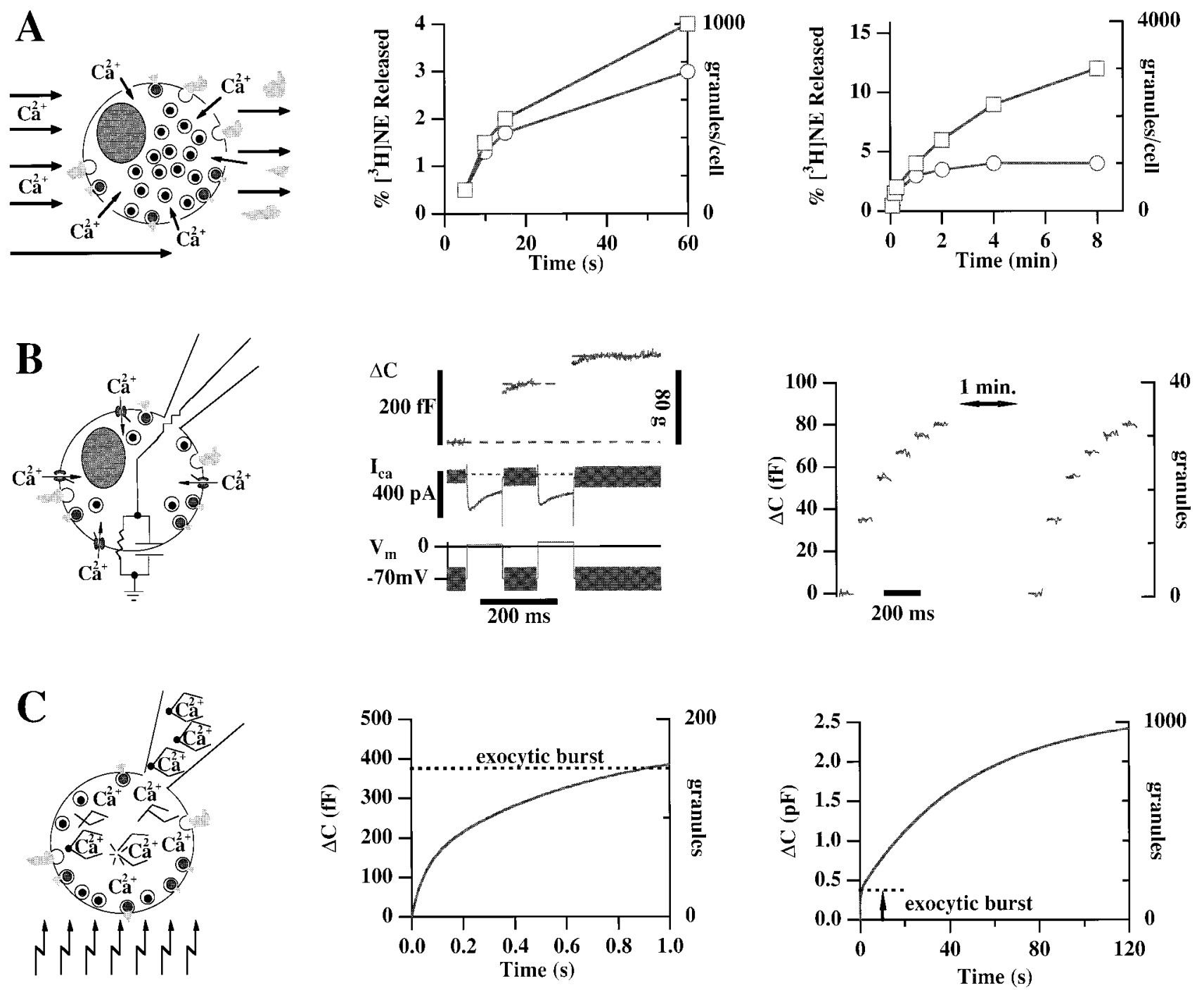

Figure 1. Techniques for measuring secretory kinetics in neuroendocrine cells. Each technique is schematically depicted in the left column, and idealized responses are shown on short (middle column) and long (right column) time scales. Each technique estimates cumulative secretion, thus decreases in the slope of the responses are consistent with the depletion of a readily releasable pool (RRP) of secretory granules. (A) Permeabilized cell technique. Idealized responses are in the absence (circles) and presence ( squares) of M gATP in a 'triggering' solution which contains $10 \mu \mathrm{M}$ $\mathrm{Ca}^{2+}$ (adapted from refs 15,17 ). The indicated number of granules secreted is based upon an estimate of 25,000 total granules per cell. ${ }^{25}$ (B) Depolarization-evoked changes in membrane capacitance $(\Delta \mathrm{C}) . \Delta \mathrm{C}$ ( reflecting cumulative exocytosis) is estimated from basic analysis of the equivalent circuit depicted in the left panel. ${ }^{28}$ The indicated number of granules secreted is based upon an estimate of $2.5 \mathrm{fF} /$ granule. ${ }^{27}$ Response to two depolarizing pulses is depicted in the middle panel. Note that the second $\Delta C$ response is smaller than the first even though the depolarizing potentials $\left(\mathrm{V}_{\mathrm{m}}\right)$ have been adjusted to give similar $\mathrm{Ca}^{2+}$ currents $\left(\mathrm{I}_{\mathrm{Ca}}\right) .{ }^{12}$ The right panel depicts idealized responses to two trains of depolarizations ( 20 ms pulses @ $5 \mathrm{~Hz}$ ) separated by one minute. The repetitive pulses demonstrate the exhaustion of the RRP which recovers during the 1 minute inter-train interval. (C) Idealized $\Delta C$ response elicited by uniform elevation of $\left[\mathrm{Ca}^{2+}\right]_{i}$ to $10 \mu \mathrm{M}$ upon photolysis of caged $\mathrm{Ca}^{2+}$. The middle panel depicts the 'exocytic burst' prominent in the first second after flash photolysis whereas the right panel shows the same response on a longer time scale. The pipette solution contains no MgATP. 
rate of exocytosis and can be used to estimate the size of the readily-releasable pool. Initial estimates of pool size generated in this manner were on the order of 100-200 granules ${ }^{3,14}$ quite a bit smaller than the estimate of the 'primed' pool in permeabilized cell studies. Later studies indicate that, under some conditions, the most readily-releasable pool size may be even smaller, consisting of only a dozen or so granules. ${ }^{11,12}$ Interestingly, the size of the readily releasable pool appears to increase upon transient elevations of $\left[\mathrm{Ca}^{2+}\right]_{i}$ to a few hundred nanomolar, ${ }^{3}$ corroborating previous results from biochemical studies that calcium may be involved in earlier steps in addition to the triggering step. ${ }^{15}$

Buffered $\mathrm{Ca}^{2+}$ solutions can be introduced into the cell through the patch pipette and the rate of exocytosis measured in an experimental approach called ' $\mathrm{Ca}^{2+}$ dialysis'. The maximum rate of exocytosis that is measured this way is generally much smaller than that obtained through membrane depolarization. ${ }^{30} \mathrm{~A}$ likely explanation for this is that the readily releasable pool becomes exhausted during the initial phases of $\mathrm{Ca}^{2+}$ entry from the pipette, when the $\left[\mathrm{Ca}^{2+}\right]_{i}$ is still rising and is still much lower than that of the pipette solution. Thus $\mathrm{Ca}^{2+}$ dialysis experiments are not a good way to estimate the rates of final steps of exocytosis. Rather, the rates of exocytosis measured by $\mathrm{Ca}^{2+}$ dialysis have been interpreted as the rate of granule mobilization. ${ }^{14,30}$ This putative mobilization rate has been modeled as having a Michaelis-M enten type dependence on $\left[\mathrm{Ca}^{2+}\right]_{i}$ with a $\mathrm{Kd}$ of $1.2 \mu \mathrm{M}$ and a maximal rate of about 18 granules/ $\mathrm{s}^{14}$ These values are quite comparable to those obtained from permeabilized cells, which secrete a maximum of about 20 granules/ $\mathrm{s}$ from $30 \mathrm{~s}-3 \mathrm{~min}$ after the elevation of $\left[\mathrm{Ca}^{2+}\right]_{\mathrm{i}}{ }^{15}$

Probing secretory kinetics using depolarizing pulses also suffers from some important limitations. The decrease in the rate of secretion with multiple depolarizing pulses may simply reflect the inactivation of $\mathrm{Ca}^{2+}$ currents. One way to address this issue is to apply depolarizing pulses of appropriate magnitude to ensure a non-decreasing total $\mathrm{Ca}^{2+}$ influx (refs 3,12 , also see Figure 1B middle panel). However, a further problem remains. $\left[\mathrm{Ca}^{2+}\right]_{i}$ levels within the cell are not uniform during a depolarization. Naturally, $\left[\mathrm{Ca}^{2+}\right]_{i}$ is highest near the mouth of open $\mathrm{Ca}^{2+}$ channels and a radial $\mathrm{Ca}^{2+}$ gradient exists during a depolarization. ${ }^{31}$ The possibility that $\mathrm{Ca}^{2+}$ channels may be clustered into 'hot spots' introduces another level of complexity. ${ }^{32}$ Without knowing the true time course of $\left[\mathrm{Ca}^{2+}\right]_{i}$ at the release sites, interpretation of the kinetics of exocytosis is complicated. Clearly a method for rapidly and uniformly elevating $\left[\mathrm{Ca}^{2+}\right]_{i}$ is desirable and is provided by the use of caged $\mathrm{Ca}^{2+}$ compounds.

\section{Caged $\mathrm{Ca}^{2+}$ experiments}

Caged $\mathrm{Ca}^{2+}$ compounds such as DM-Nitrophen ${ }^{33}$ have a very high affinity for $\mathrm{Ca}^{2+}$ which then decreases by many orders of magnitude upon photolysis with UV illumination. $\mathrm{Ca}^{2+}$-loaded cages can be introduced into a cell through a patch pipette and photolysed within about $1 \mathrm{~ms}$ via a flash of UV light. The amplitude of the resulting step in $\left[\mathrm{Ca}^{2+}\right]_{i}$ depends on the intensity of the flash (which determines the percentage of the cage that is photolysed) and can be measured using a low-affinity $\mathrm{Ca}^{2+}$ indicator such as furaptra.

The capacitance response to step elevation of $\left[\mathrm{Ca}^{2+}\right]_{i}$, as expected, indicates an initially high rate of exocytosis which then rapidly declines. ${ }^{9,10,16}$ Figure 1C illustrates the technique and an idealized response. The rapid initial response has been termed the 'exocytic burst' 16 and proceeds with two kinetic components in chromaffin cells (i.e. the initial rise in membrane capacitance is usually fitted with a sum of two exponentials $\left.{ }^{10}\right)$. In the experiments of Heinemann et al, ${ }^{10}$ the amplitude of each kinetic component is roughly equal and corresponds to about 100 granules. Both of the kinetic rates of the exocytic burst are faster with higher $\left[\mathrm{Ca}^{2+}\right]_{i}$ and are therefore thought to reflect the $\mathrm{Ca}^{2+}{ }^{2}$-sensitivity of the final step(s) of exocytosis. The faster kinetic rate saturates in high $\left[\mathrm{Ca}^{2+}\right]_{i}$ at about $1000 \mathrm{~s}^{-1}$ ( or 40,000 granules/ s!) whereas the slower rate saturates at about $100 \mathrm{~s}^{-1}$. For $\left[\mathrm{Ca}^{2+}\right]_{\mathrm{i}}=10 \mu \mathrm{M}$, the kinetic rates are about $20 \mathrm{~s}^{-1}$ and $2 \mathrm{~s}^{-1}$, respectively.

Similar types of experiments have been performed in another neuroendocrine cell, the pituitary melanotroph. ${ }^{16}$ The primary difference between the two cell types is that the fastest kinetic component which is seen in most (but not all) chromaffin cells appears to be absent in melanotrophs.

Much slower kinetic components are also present in both cell types. ${ }^{9,10,16}$ Whereas about 150 granules are released within about $100 \mathrm{~ms}$ in the 'exocytic burst' in melanotrophs, roughly an additional 1000 are added over the next 5 seconds. ${ }^{16}$ This 'slow phase' can be eliminated by intracellular acidification to $\mathrm{pH} 6.2$, whereas the exocytic burst is unaffected. ${ }^{16} \mathrm{~A}$ similar component (paradoxically termed 'fast secretion' by 
Neher and Zucker) is present in chromaffin cells when $\left[\mathrm{Ca}^{2+}\right]_{\mathrm{i}}$ is elevated about $80 \mu \mathrm{M} .{ }^{9}$ In this case about 200 granules are released with a time constant of several seconds. Finally, an 'ultraslow' phase of exocytosis was noted in melanotrophs which proceeds at a rate of about 26 granules per second over many tens of seconds at $22^{\circ} \mathrm{C}^{16}$ Interestingly, this rate is almost 10 -fold greater at $32^{\circ} \mathrm{C}$ than at $22^{\circ} \mathrm{C} \cdot{ }^{16} \mathrm{~A}$ similar kinetic component, which is comparable to rates measured in ' $\mathrm{Ca}^{2+}$ dialysis' experiments, was reported by Neher and Zucker in chromaffin cells. ${ }^{9}$ Temperature-dependent effects on slower phases of secretion have also been noted in pancreatic $B$ cells. $^{34}$

O ne important result from caged $\mathrm{Ca}^{2+}$ experiments is the demonstration that there are additional steps after MgATP-dependent 'priming'. The RRP found using capacitance measurements is clearly smaller than the 'primed' pool assayed biochemically. In addition, all of the kinetic components found in caged $\mathrm{Ca}^{2+}$ experiments occur in the total absence of MgATP. Recently, Parsons et al ${ }^{7}$ compared capacitance responses in the presence and absence of MgATP and found that only the very slowest phase of exocytosis is sensitive to MgATP. Thus MgATP-dependent priming is a relatively early step in the sequence of reactions which lead to exocytosis.

Another important result from caged $\mathrm{Ca}^{2+}$ experiments is that the size of the RRP can be modulated biochemically. Treating chromaffin cells with protein kinase $C$ (PKC) activators leads within seconds to an increase in $\mathrm{Ca}^{2+}$-triggered secretion (e.g. refs $8,12,38,39)$. Measurements on permeabilized cells led to the hypothesis that PKC acts at a 'late' step; ${ }^{38}$ however, it was not possible to discern whether the enhanced secretion was due to an increase in the calcium sensitivity of the secretory machinery or to an increase in the RRP. A study using depolarizationevoked capacitance measurements was suggestive that PKC enhances the RRP and showed an increase in the number of morphologically defined 'docked' granules. ${ }^{8}$ With caged $\mathrm{Ca}^{2+}$ stimulation and capacitance measurements, it was possible to demonstrate unequivocally an increase in the size of the RRP, as evidenced by a larger exocytic burst. ${ }^{12}$ The calcium sensitivity of exocytosis could also be directly evaluated from the kinetic rates and did not shift appreciably upon activation of PKC. ${ }^{12}$

\section{Kinetic model of exocytosis in chromaffin cells}

In summary, several experimental approaches show that maintained elevation of $\left[\mathrm{Ca}^{2+}\right]_{i}$ leads to an initial rapid phase of exocytosis followed by multiple slower kinetic components. The unexpected richness in the time course of secretion can be modeled in a number of different ways (for example, see ref 43 for a 'parallel' model of secretion in PC-12 cells), however, a linear arrangement such as depicted in Figure 2 is most often used. ${ }^{7,10,14,16} \mathrm{H}$ ere it is assumed that secretory granules are arranged in a number of functional pools corresponding to steps in maturation to a fully fusion-component state. Initially, only this readily releasable pool $\left(V_{0}\right)$ is released upon elevation of $\left[\mathrm{Ca}^{2+}\right]_{i}$. Later, secretion slows as earlier steps in granule maturation become rate-limiting.

It is important to recognize that such models are intended only to summarize current experimental findings, stimulate discussion and to aid in the design of future experiments. They are not intended to be the 'final word' on the mechanisms of exocytosis and will undoubtedly change as more data become available.

\section{Current issues}

\section{Which kinetic step corresponds to granule docking?}

The concept of functional pools presented above is based upon experimental observations of the kinetics of exocytosis. Presumably one of the kinetically defined pools corresponds to the morphologically defined 'docked' pool of secretory granules. Recently, Parson et $\mathrm{al}^{7}$ have used membrane capacitance measurements to show that about 800 granules can be released in the absence of MgATP - a value quite similar to their estimate of the number of granules in close proximity to the plasma membrane. Based upon this correlation, they argue that granule docking is closely associated with steps that require ATP hydrolysis. This would suggest that the docking step may occur relatively early and a number of additional reactions may be required before a granule is fully fusion-competent. Estimation of the number of docked granules are controversial, however, with values as low as about 200 per cell being reported. ${ }^{8}$ This latter estimate is more compatible with the size of the exocytic burst and would place granule docking as one of the final steps before exocytosis. 
Is there an 'immediately-releasable pool' (IRP) located near $\mathrm{Ca}^{2+}$ channels? H ow large IS the RRP?

Recently, Horrigan and Bookman ${ }^{11}$ have proposed that only a dozen or so granules are located near functional $\mathrm{Ca}^{2+}$ channels (the 'IRP') and only these are released with brief depolarizations. Other granules are located more distant from the channels and are released only with prolonged or repeated depolarizations. This hypothesis is based upon two observations. First, only the IRP is released in cells with small $\mathrm{Ca}^{2+}$ currents or when a high intracellular concentration of $\mathrm{Ca}^{2+}$ buffer is used. Second, the IRP consists of only about 17 granules, whereas the pool elicited with multiple pulses contains about 170 granules. The size of the larger pool is consistent with the size of the exocytic burst measured in caged $\mathrm{Ca}^{2+}$ experiments ${ }^{10}$ whereas the IRP is an order of magnitude smaller. Gillis \& al $^{12}$ have also reported depolarization-based estimates of pool size that are much smaller than estimates derived from caged $\mathrm{Ca}^{2+}$ experiments.

Although the hypothesis of segregation of the RRP into two granule populations based on proximity to $\mathrm{Ca}^{2+}$ channels is attractive, and there are other data that support this idea, ${ }^{36,37}$ further experiments are needed to test the hypothesis. It is important to recognize that the size of the RRP is highly variable, depending strongly on the previous stimulation history of the cell, in particular with regard to elevations of $\left[\mathrm{Ca}^{2+}\right]_{i}$, and on the activation of protein kinases. $^{12}$

\section{Are sequential models such as Figure 2 actually useful for understanding the dynamics of exocytosis in chromaffin cells?}

Sequential models of the steps leading to exocytosis have recently come under sharp criticism from the laboratory of M.C. Nowycky. Seward and Nowycky ${ }^{29}$ report that the first train of depolarizing pulses leads to a rapid depletion of the secretory response consistent with the depletion of a RRP. However, subsequent bouts of stimulation lead to a very different pattern of exocytosis, whereby later pulses lead to greater amounts of release than earlier pulses. This kinetic pattern is termed 'threshold secretion' because the rate of secretion increases after a certain threshold of $\mathrm{Ca}^{2+}$ has entered the cell. Engisch and Nowycky ${ }^{35}$ show that, during perforated patch recording, the amount of exocytosis elicited by a depolarizing step depends simply on the total number of $\mathrm{Ca}^{2+}$ ions that enter the cell during the pulse (' $Q$ '). Since different depolarization protocols probably result in very different $\left[\mathrm{Ca}^{2+}\right]_{i}$ time courses and spatial gradients, this result appears inconsistent with the basic assumption that a steeply $\left[\mathrm{Ca}^{2+}\right]_{i}$ dependent process controls the rate of exocytosis from a small releasable pool of granules.

Clearly, relatively simple models such as Figure 2 are insufficient to describe the full richness of exocytosis evident in chromaffin cells, and the concept of monotonically decreasing secretory rates is an oversimplification. H owever, at least some features of exocytosis reported by the Nowycky lab can be reconciled with such a model. A RRP consisting of 10 or so granules could be overlooked during the initial 'unresponsive' period of 'threshold secretion'. The threshold itself could result from the $\mathrm{Ca}^{2+}$-dependent mobilization steps previously observed.

A tight correlation between exocytosis and ' $Q$ ' would be predicted from the model if the following two conditions held: (1) $\mathrm{Ca}^{2+}$ channels and release sites are not closely co-localized. If true, then differences in the $\left[\mathrm{Ca}^{2}\right]_{i}$ profile near individual channels under different depolarization protocols would have little effect. There is some experimental evidence that $\mathrm{Ca}^{2+}$ channels are not as tightly coupled to release sites in chromaffin cells as they are in neurons. ${ }^{36,37}$ (2) The rate of exocytosis is linearly dependent on $\left[\mathrm{Ca}^{2+}\right]_{i}$. In this case a large amount of $\mathrm{Ca}^{2+}$ influx for a short time could lead to the same amount of secretion as a small influx over a longer time. Whereas there is strong evidence that the final release step is steeply dependent on $\left[\mathrm{Ca}^{2+}\right]_{\mathrm{i}}{ }^{10}$ earlier steps (e.g. reaction $V_{1}->V_{0}$ in Figure 2 ) may have a shallower $\mathrm{Ca}^{2+}$-dependence., ${ }^{9,10,14,15,30}$ These earlier steps will dominate the overall secretory response if the RRP becomes depleted.

Finally, experimental variability suggests that, although the correlation between exocytosis and ' $Q$ ' is high, significant deviations from a strict one-to-one relationship could be buried in the experimental 'noise'.

\section{Is 'adaptation' of the $\mathrm{Ca}^{2+}$ sensor responsible for the transient nature of secretion?}

While this review was in proof, a study measuring exocytosis elicited by photolysis of caged $\mathrm{Ca}^{2+}$ at the squid giant synapse was published. ${ }^{44} \mathrm{H}$ su et al found that the amount of exocytosis was sensitive to the $\left[\mathrm{Ca}^{2+}\right]_{i}$ level achieved upon photolysis whereas the rate of secretory decline was relatively insensitive to the $\left[\mathrm{Ca}^{2+}\right]_{i}$ value. From this and other observations, 


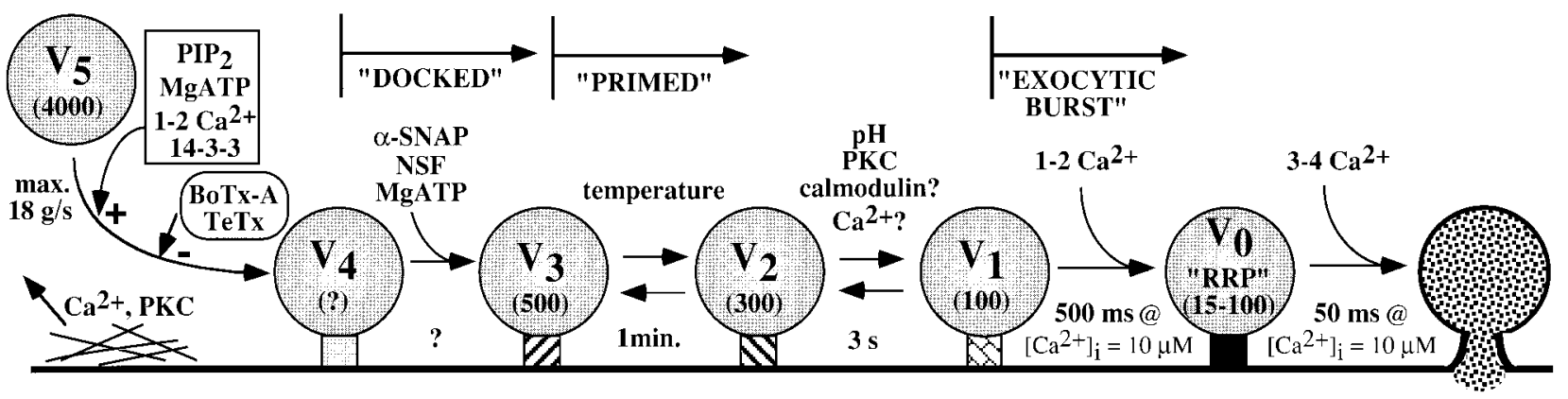

Figure 2. Highly hypothetical model of the kinetic steps leading to exocytosis. The approximate number of granules in each putative state is indicated in parentheses, and the approximate reaction times are indicated below the arrows. Left: Granule docking may require the disruption of a cortical actin 'barrier', which is facilitated upon activation of protein kinase C (PKC) or elevation of $\left[\mathrm{Ca}^{2+}\right]_{i}$ (e.g. ref 8). The physically 'docked' pool $\left(\mathrm{V}_{0}-\mathrm{V}_{4}\right)$ may be identical to the functional pool that is 'primed' by MgATP $\left(\mathrm{V}_{0}-\mathrm{V}_{3}\right) .{ }^{7}$ Cofactors involved in 'priming' may include enzymes which maintain polyphosphoinositide lipids $\left(P P_{2}\right.$, refs $\left.19-21\right), 14-3-3$ proteins, ${ }^{23}$ and $\mathrm{Ca}^{2+3,15,30}$ Botulinum toxin type $\mathrm{A}$ (BoTx-A) and tetanus toxin (TeTx) block priming. ${ }^{42}$ The dissolution of the putative $20 \mathrm{~S}$ docking/ fusion complex (which includes the soluble proteins $\alpha$ SNAP and NSF) also requires M gATP, and is thus included as a 'priming' step. ${ }^{22,23} \mathrm{~A}$ temperaturedependent step follows 'priming' ${ }^{24,16}$ which may be identical to a slow 'mobilization' step observed in caged $\mathrm{Ca}^{2+}$ experiments in chromaffin cells. ${ }^{9}$ This is followed by a step inhibited by intracellular acidification ${ }^{16}$ in melanotrophs. A step with similar kinetics is seen in chromaffin cells when $\left[\mathrm{Ca}^{2+}\right]_{i}$ is elevated above $80 \mu \mathrm{M} .{ }^{9}$ PKC may enhance this step since it works after the temperaturesensitive step ${ }^{38}$ but before the final $\mathrm{Ca}^{2+}$ sensitive reactions. ${ }^{12}$. Calmodulin has also been proposed to work at a late step. ${ }^{23,41}$ The final two steps correspond to the rapid exocytic burst seen in caged $\mathrm{Ca}^{2+}$ experiments. ${ }^{10}$ The reaction times correspond to $\left[\mathrm{Ca}^{2+}\right]_{i}=10 \mu \mathrm{M} .{ }^{10}$ The size of the RRP $\left(\mathrm{V}_{0}\right)$ may vary from about $15^{11,12}$ to 100 or more granules $3,9,10,12$ depending on prior exposure of the cell to $\mathrm{Ca}^{2+}$ and/ or activation of PKC.

they came to the conclusion that the declining rate of secretion following the flash is due to an adaptation of the $\mathrm{Ca}^{2+}$ receptor to a constant $\left[\mathrm{Ca}^{2+}\right]_{i}$ value rather than a depletion of a vesicle pool. Whereas the $\mathrm{Ca}^{2+}$ sensor in chromaffin cells may also be sensitive to the rate of change of $\mathrm{Ca}^{2+}$ (e.g. see ref 2), it should be noted that in chromaffin cells, ${ }^{10,12}$ as well as in melanotrophs ${ }^{16}$ and bipolar nerve terminals, ${ }^{45}$ the rate of exocytosis is exquisitely sensitive to the $\mathrm{Ca}^{2+}$ level, whereas the size of the exocytic burst is virtually insensitive to $\left[\mathrm{Ca}^{2+}\right]_{i}$ as long as the threshold for secretion is exceeded.

\section{Concluding remarks}

Whereas linear models such as Figure 2 can describe most experimental results obtained in chromaffin cells, they are by no means unique. An actual understanding of the steps involved in exocytosis will require the identification of the molecular reactions which underlie them. Recent major advances in identifying the molecules involved in exocytosis suggest that relating kinetic steps of exocytosis to specific molecular reactions is a realistic goal for the near future.

\section{Acknowledgement}

We would like to thank Prof. Erwin Neher for a critical reading of the manuscript.

\section{References}

1. Douglas WW (1968) Stimulus-secretion coupling: the concept and clues from chromaffin and other cells. Br J Pharmacol 34:451-474

2. Knight DE, Baker PF (1982) Calcium-dependence of catecholamine release from bovine adrenal medullary cells after exposure to intense electric fields. J Membr Biol 68:107-140

3. von Rüden L, Neher E (1993) A Ca-dependent early step in the release of catecholamines from adrenal chromaffin cells. Science 262:1061-1065

4. Gillis KD, Misler S (1992) Single cell assay of exocytosis from pancreatic islet B cells. Pflügers Arch 420:121-123

5. Lim NF, Nowycky MC, Bookman RJ (1990) Direct measurement of exocytosis and calcium currents in single vertebrate nerve terminals. Nature 344:449-451

6. Burgoyne RD (1991) Control of exocytosis in adrenal chromaffin cells. Biochim Biophys Acta 1071:174-202 
7. Parsons TD, Coorssen JR, Horstmann H, Almers W (1995) Docked granules, the exocytic burst and the need for ATP hydrolysis in endocrine cells. Neuron 15:1085-1096

8. Vitale ML, Seward EP, Trifaró JM (1995) Chromaffin cell cortical actin network dynamics control the size of the releaseready vesicle pool and the initial rate of exocytosis. Neuron 14:353-363

9. Neher E, Zucker RS (1993) Multiple calcium-dependent processes related to secretion in bovine chromaffin cells. Neuron 10:21-30

10. Heinemann C, Chow RH, Neher E, Zucker RS (1994) Kinetics of the secretory response in bovine chromaffin cells following flash photolysis of caged $\mathrm{Ca}^{2+}$. Biophys J 67:2546-2557

11. Horrigan FT, Bookman RJ (1994) Releasable pools and the kinetics of exocytosis in adrenal chromaffin cells. Neuron 13:1119-1129

12. Gillis KD, Mößner R, Neher E (1996) Protein kinase C enhances exocytosis from chromaffin cells by increasing the size of the readily releasable pool of secretory granules. Neuron 16:1209-1220

13. Michelena P, Vega T, Montiel C, López MG, García-Perez LE, Gandía L, García AG (1995) Effects of tyramine and calcium on the kinetics of secretion in intact and electroporated chromaffin cells superfused at high speed. Pflügers Arch 431:283-296

14. H einemann C, von Rüden L, Chow RH, Neher E (1993) A twostep model of secretion control in neuroendocrine cells. Pflügers Arch 424:105-112

15. Bittner MA, H olz RW (1992) Kinetic analysis of secretion from permeabilized adrenal chromaffin cells reveals distinct components. J Biol Chem 267:16219-16225

16. Thomas P, Wong JG, Lee AK, Almers W (1993) A low affinity $\mathrm{Ca}^{2+}$ receptor controls the final steps in peptide secretion from pituitary melanotrophs. Neuron 11:93-104

17. Holz RW, Bittner MA, Peppers SC, Senter RA, Eberhard DA (1989) MgATP-independent and MgATP-dependent exocytosis. J Biol Chem 264:5412-5419

18. Hay JC, Martin TFJ (1992) Resolution of regulated secretion into sequential MgATP-dependent and calcium-dependent stages mediated by distinct cytosolic proteins. J Cell Biol 119:139-151

19. Hay JC, Martin TFJ (1993) Phosphatidylinositol transfer protein required for ATP-dependent priming of $\mathrm{Ca}^{2+}$-activated secretion. Nature 366:572-575

20. Hay JC, Fisette PL, Jenkins GH, Fukami K, Takenawa T, Anderson RA, Martin TFJ (1995) ATP-dependent inositide phosphorylation required for $\mathrm{Ca}^{2+}$-activated secretion. Nature 374:173-177

21. Eberhard DA, Cooper CL, Low M G, Holz RW (1990) Evidence that the inositol phospholipids are necessary for exocytosis. Biochem J 268:15-25

22. Söllner $T$, Whiteheart SW, Brunner $M$, Erdjument-Bromage $H$, Geromanos S, Tempst P, Rothman JE (1993) SNAP receptors implicated in vesicle targeting and fusion. Nature 362:318-324

23. Chamberlain LH, Roth D, Morgan A, Burgoyne RD (1995) Distinct effects of a-SNAP, 14-3-3 proteins, and calmodulin on priming and triggering of regulated exocytosis. J Cell Biol 130:1063-1070

24. Bittner MA, Holz RW (1992) A temperature-sensitive step in exocytosis. J Biol Chem 267:16226-16229

25. Phillips JH, Burridge K, Wilson SP, Kirschner N (1983) Visualization of the exocytosis/ endocytosis secretory cycle in cultured adrenal chromaffin cells. J Cell Biol 97:1906-1917
26. Hamill OP, Marty A, Neher E, Sakmann B, Sigworth FJ (1981) Improved patch-clamp techniques for high resolution current recordings from cell and cell-free membrane patches. Pflügers Arch 391:85-100

27. Neher E, Marty A (1982) Discrete changes of cell membrane capacitance observed under conditions of enhanced secretion in bovine adrenal chromaffin cells. Proc Natl Acad Sci USA 79:6712-6716

28. Gillis KD (1995) Techniques for membrane capacitance measurements. Single-channel Recording, 2nd ed. (Sakmann B, Neher $E$, eds) pp 155-198. Plenum Press, New York

29. Seward EP, N owycky MC (1996) Kinetics of stimulus-coupled secretion in dialyzed bovine chromaffin cells in response to trains of depolarizing pulses. J Neurosci 16:553-562

30. Augustine GJ, Neher E (1992) Calcium requirements for secretion in bovine chromaffin cells. J Physiol Lond 450:247-271

31. Neher E, Augustine GJ (1992) Calcium gradients and buffers in bovine chromaffin cells. J Physiol Lond 450:273-301

32. Monck JR, Robinson IM, Escobar AL, Vergara JL, Fernandez JM (1994) Pulsed laser imaging of rapid $\mathrm{Ca}^{2+}$ gradients in excitable cells. Biophys J 67:505-514

33. Kaplan JH, Ellis-Davies GCR (1988) Photolabile chelators for rapid photolytic release of divalent cations. Proc Natl Acad Sci USA 86;6571-6575

34. Renström E, Eliasson L, Bokvist K, Rorsman P (1996) Cooling inhibits exocytosis in single mouse pancreatic B-cells by suppression of granule mobilization. J Physiol Lond 494:41-52

35. Engisch KL, N owycky MC (1996) Calcium dependence of large dense-cored vesicle exocytosis evoked by calcium influx in bovine adrenal chromaffin cells. J Neurosci 16:1359-1369

36. Chow RH, Klingauf J, Heinemann C, Zucker RS, Neher E (1996) Mechanisms determining the time course of secretion in neuroendocrine cells. Neuron 16:369-376

37. Zhou Z, Misler S (1995) Action potential-induced quantal secretion of catecholamines from rat adrenal chromaffin cells. J Biol Chem 270:3498-3505

38. Bittner MA, Holz RW (1993) Protein kinase C and clostridial neurotoxins affect discrete and related steps in the secretory pathway. Cell Mol Neurobiol 13:649-664

39. Knight DE, Baker PF (1983) The phorbiol ester TPA increases the affinity of exocytosis for calcium in 'leaky' adrenal medullary cells. FEBS Lett 160:98-100

40. Smith CB, Betz WJ (1996) Simultaneous independent measurement of endocytosis and exocytosis. Nature 380:531-534

41. Kibble AV, Burgoyne RD (1996) Calmodulin increases the initial rate of exocytosis in adrenal chromaffin cells. Pflügers Arch 431:464-466

42. Lawrence GW, Weller U, Dolly JO (1994) Botulinum A and the light chain of tetanus toxins inhibit distinct stages of MgATPdependent catecholamine exocytosis from permeabilised chromaffin cells. Eur J Biochem 222:325-333

43. Kasai $\mathrm{H}$, Takagi $\mathrm{H}$, Ninomiya $Y$, Kishimoto $\mathrm{T}$, I to $\mathrm{K}$, Yoshida $\mathrm{A}$, Yoshioka T, Miyashita Y (1996) Two components of exocytosis and endocytosis in phaeochromocytoma cells studied using caged $\mathrm{Ca}^{2+}$ compounds. J Physiol Lond 494:53-65

44. H su S-F, Augustine GJ, Jackson MB (1996) Adaptation of $\mathrm{Ca}^{2+}$ triggered exocytosis in presynaptic terminals. Neuron 17:501-512

45. Heidelberger R, Heinemann C, Neher E, Matthews G (1994) Calcium dependence of the rate of exocytosis in a synaptic terminal. Nature 371:513-515 